\title{
Delayed Pattern Discrimination in Patients with Unilateral Temporal Lobe Damage
}

\author{
Mark W. Greenlee, Johannes Rischewski, Thomas Mergner, and Wolfgang Seeger \\ Neurologische Universitätsklinik and Neurochirurgische Universitätsklinik, D-7800 Freiburg, Germany
}

\begin{abstract}
Behavioral and neurophysiological studies in macaque monkeys suggest a role of the inferior temporal cortex in pattern discrimination and visual memory. To determine whether this cortical area is also involved in human short-term visual memory, we measured spatial frequency discrimination thresholds for sequentially presented stimuli in 17 patients with unilateral, postoperative focal damage to the temporal cortex ( 11 left, 6 right hemisphere). These results are compared to those of 17 age-matched control subjects. Contrast detection thresholds and difference thresholds for spatial frequency were determined for spatially truncated sine wave gratings presented in the left and right visual fields. Detection thresholds were measured for sine wave gratings in a spatial two-alternative forced-choice procedure for three spatial frequencies $[2.5,5$, and 10 cycles (c)/degree] for each hemifield. Discrimination thresholds were determined for two gratings sequentially presented either $4^{\circ}$ to the left or right of fixation. Grating contrast was five times the value of detection threshold and reference frequency was 5 c/degree. Within each trial, the gratings were separated in time by 1, 3, and 10 sec interstimulus intervals (ISIs), and subjects signaled which grating had the higher spatial frequency. The results indicate that (1) contrast detection thresholds overall did not differ between patient and control groups; (2) spatial frequency discrimination thresholds were, however, significantly elevated in patients and this elevation was significantly more pronounced in the visual field contralateral to the damaged hemisphere; and (3) patients with inferotemporal damage exhibited higher discrimination thresholds for the longest ISI, whereas patients with medial/ superior temporal lobe damage did not show this effect. The results suggest that visual areas in human temporal cortex are involved in the higher visual processes underlying delayed pattern discrimination.
\end{abstract}

[Key words: pattern discrimination, inferior temporal cortex, cortical lesions, visual memory, contrast sensitivity, spatial vision, psychophysics]

Received July 20, 1992; revised Dec. 8, 1992; accepted Dec. 21, 1992.

This research was supported by the Deutsche Forschungsgemeinschaft (SFB 325, B4). M.W.G. is a Feodor-Lynen Fellow of the Alexander von Humboldt Foundation (Bonn). Part of this work was used to fulfill the requirements for a medical degree at the University of Freiburg by J.R. We express our appreciation to the persons who served as subjects in the experiments and to Drs. L. Spillmann and S. Magnussen and C. H. Lücking for their helpful comments.

Correspondence should be addressed to Dr. Mark W. Greenlee, Department of Neurophysiology, University of Freiburg, Hansastrasse 9, 7800 Freiburg, Germany.

Copyright (C) 1993 Society for Neuroscience $0270-6474 / 93 / 132565-10 \$ 05.00 / 0$
Converging evidence from neurophysiological investigations in higher mammals and psychophysical studies in human observers indicate that visual images are encoded along the dimensions of orientation, spatial frequency (relative size), position, contrast, and color, and, for moving stimuli, the direction and velocity of this motion (De Valois and De Valois, 1988; Spillmann and Werner, 1991). Visually guided behavior demands, in addition to accurate coding, the short- and long-term storage of visual images, as well as their instantaneous recall from this storage. In monkeys, evidence from lesion and cortical cooling studies suggests a role of visual areas in the temporal lobe in pattern discrimination (Mishkin and Pribram, 1954; Cowey and Gross, 1970; Dean, 1976; Fuster et al., 1981; Sahgal et al., 1983; Horel et al., 1987), as well as in the discrimination of luminancedefined and motion-defined contours (Britten et al., 1992). Single-unit recordings in the macaque monkey indicate that the stimulus-response characteristics of the cells in the inferotemporal (IT) cortex are different from those of striate cells with respect to their receptive field size and stimulus selectivity (Gross et al., 1972; Desimone and Gross, 1979; Parrett et al., 1982; Desimone et al., 1984). Compared to cells in area V1, the cells in the IT area have large $\left(>20^{\circ}\right)$ receptive fields. Their responses can depend on the size and orientation of simple and complex stimuli (Gross et al., 1972; Desimone et al., 1984; Tanaka et al., 1991). More recent studies in monkeys performing discrimination tasks indicate that the responses of cells in the extrastriate area V4 (Haenny and Schiller, 1988; Haenny et al., 1988) and in the IT cortex (Mikami and Kubota, 1980; Miyashita and Chang, 1988; Saito, 1989; Miller et al., 1991) can vary depending on the novelty of the stimulus, as well on the type of memory task being performed. Such response modulations might, in part, reflect the neural processes involved in delayed pattern discriminations.

In humans, findings from positron emission tomography of regional cerebral blood flow indicate that extrastriate areas are involved in processes underlying the perception of color, shape, and speed of moving stimuli (Corbetta et al., 1991; Zeki et al., 1991) and visual imagcry (Roland and Widen, 1988). Neuropsychological studies of patients with unilateral (Kimura, 1963; Milner, 1968) and bilateral (Damasio et al., 1982) damage to the temporal lobe suggest a deficit in visual perception and memory in complex visual recognition tasks, and more recent studies have revealed selective deficits in motion perception following occipital-temporal and occipital-parietal lobe damage (Zihl et al., 1983, 1991; Vaina, 1989; Plant and Nakayama, 1992). Psychophysical investigations of visual short-term memory in normal healthy adults, on the other hand, have shown that the retention of information concerning the spatial fre- 
quency of briefly presented sine wave gratings is very good for delays up to $10 \mathrm{sec}$ (Magnussen et al., 1990, 1991).

In the present study, we have explored delayed pattern discrimination in patients with focal, unilateral damage to the temporal cortex using the psychophysical technique of spatial freyuency discrimination. Performance in a simple detection task was compared to that of a delayed, spatial frequency discrimination task for eccentrically presented grating patches. The findings indicate that spatial frequency discrimination thresholds are significantly increased in patients with temporal lobe damage and the magnitude of this increase is more pronounced in the visual field contralateral to the damaged hemisphere.

\section{Materials and Methods}

Patients and control subjects. The observers were 17 patients who showed objective signs of a focal cortical lesion in one of the temporal lobes. The patients were selected from medical archives of the Department of Neurosurgery of the University of Freiburg. They were recruited after consulting their general practitioner or treating neurologist. The exclusion criteria were as follows: age $>74$ yrs, more than one cerebral lesion, lesions in the hippocampus or rhinal and perirhinal cortex (areas known to be involved in human memory), glioblastoma or metastases, an illdefined lesion (e.g., edema), signs of visual neglect in the case history, score of $\leq 4$ on the Corsi test (see below), radiation therapy, high-dose medication with potentially sedating drugs and/or drug intoxication. Table 1 presents a description of the patient group. Fifteen patients had undergone surgical removal of a tumor (13 cavernomas, 2 astrocytomas WHO II), which were located in or near the cortical gray matter. One patient had a well-defined ischemic lesion (PAT14) and one patient was examined prior to surgical removal of a cavernoma (PAT11). The patient group consisted of 10 males and 7 females. With one exception (PAT04) all patients were right-handed. Eleven patients had damage in the left temporal lobe (PAT01-PAT11), and six patients, in the right temporal lobe (PAT12-PAT17). In four patients (PAT09, PAT13, PAT 14, PAT 16) the lesion extended into one of the neighboring cortices. In three patients (PAT02, PAT10, PAT17) the lesions extend toward the hippocampus or the rhinal or perirhinal cortex, without, however, directly involving them. Twelve patients were receiving antiepileptic therapy. The 17 control subjects were matched on age, sex, and handedness. The mean age of the patients was 39.2 ycars, $\mathrm{SD}=11.3$ ycars (range, 19-58 years), and that of control group was 41.1 years, SD = 16.7 years (range, $21-72$ years).

Analysis of lesion area and memory test. The location and extent of the lesioned area were determined based on the pre- and postoperative computed tomograms and magnetic resonance images, as well as on the protocol from surgery. An outline of the lesioned area was transferred onto standardized templates derived from a computed tomographic atlas (Nadjmi et al., 1991). The templates were then stacked appropriately to yield a three-dimensional representation. These reconstructions are shown for each patient in Figure 1, the darkly shaded areas representing the lesion. The patients were divided into two groups: the regionof-interest group was composed of 10 patients, in whom the lesion extended into the IT lobe (IT patients). The other group comprised scven patients with temporal lesions outside of the region of interest.

To assess general memory abilities, a neuropsychological block-tapping test was conducted, the so-called Corsi test (Milner, 1971). The test consists of nine black cubes $(2.5 \times 2.5 \times 2.5 \mathrm{~cm})$ fixed onto a gray plastic board $(28 \times 23 \mathrm{~cm})$. The nine blocks were arranged according to the original design. After instructing the patient or subject in how to perform the test, the experimenter began by tapping four of the nine blocks. In order for the trial to be scored as correct the patient or subject had to tap the same blocks in the same order. Each trial was conducted twice, each trial using a different sequence. The difficulty of the task was increased by increasing the number of blocks tapped. The resulting score was based on the number of blocks, which were correctly tapped on both trials. The mean score was $5.65 \pm 0.68$ for the patients and $5.82 \pm 0.62$ for the controls (NS).

Stimuli. Sine wave luminance gratings of vertical orientation were produced by a specially designed graphics board (VSG2, Cambridge Research Systems) and a 386 computer, which provided the control signals to a high-resolution display (DM2, Joyce Electronics). Two digital-to-analog converters yielded independent voltage outputs with 12 bit resolution. The Joyce display has a white ( $\mathrm{P} 4)$ phosphor and a frame rate of $100 \mathrm{~Hz}$, each frame consisting of 1024 raster lines, with an average mean luminance of $200 \mathrm{~cd} / \mathrm{m}^{2}$. The control voltage-luminance characteristic of the display is linear within the range used, which was achieved by appropriate look-up tables and calibrated with a spot photometer. The contrast of the grating stimuli was modulated in space and time by Gaussian envelopes (cf. Marcelja, 1980). In the temporal domain, the Gaussian envelope had a time constant of $110 \mathrm{msec}$; the entire duration was thus approximately $700 \mathrm{msec}$. In the space domain the Gaussian had a constant of $0.5^{\circ}$ along the horizontal, which yielded a spatial frequency bandwidth of approximately 0.25 octave for the 5 cycle (c)/degree reference spatial frequency. The center of the Gaussian envelope was offset by $4^{\circ}$ on either side of the centrally located fixation point. The envelope extended vertically along the entire height of the display. Contrast was defined by the Michelson equation $C=\left(L_{\max }-\right.$ $\left.L_{\min }\right) /\left(L_{\max }+L_{\min }\right)$, where $L_{\max }$ is the maximum luminance level, and $L_{\min }$, the minimum value. To eliminate fixed local cues, each stimulus was presented with a spatial phase that was random with respect to the center of the Gaussian envelope.

Procedure. Two measurements were conducted. In both experiments, the observers binocularly viewed the display from a distance of 0.84 $\mathrm{m}$. Constant distance and head orientation were maintained by having the observer place his or her head on a chin-forehead rest. The observers were instructed to fixate a centrally located black Letraset circle that was attached to the glass surface of the display. In the first measurement, contrast detection thresholds were determined in a two-alternative forcedchoice procedure. Each trial was announced by a computer-generated auditory tone. Within each trial, a stimulus was presented randomly to the left or right of the fixation point. The observer's task was to signal whether the stimulus was presented left or right of fixation. Detection thresholds were determined by a staircase procedure, in which one of 40 contrast levels was presented. An estimate of threshold was made using a maximum-likelihood procedure, the so-called Best-PEST algorithm, parametric estimation by sequential testing (Lieberman and Pentland, 1982). Contrast detection thresholds were measured for three spatial frequencies $(2.5,5$, and $10 \mathrm{c} /$ degree) for the left (LVF) and right (RVF) visual fields separately.

In the second experiment, spatial frequency discrimination thresholds were determined for grating stimuli, the contrast of which was adjusted to be five times the value of detection threshold. This value was determined for each observer and each visual field separately. In these measurements two gratings were presented, one having the reference spatial frequency of $5 \mathrm{c} /$ degree $(f)$, and the other having a spatial frequency corresponding to $f-\Delta f$ or $f+\Delta f$. The order in which the reference and test gratings were presented was randomly determined by the computer, which also determined whether $\Delta f$ was subtracted from or added to the reference spatial frequency. The presentation of the test and reference grating was separated in time by an interstimulus interval (ISI) that was either 1,3 , or $10 \mathrm{sec}$ in duration. The observer's task was to signal which grating had the higher spatial frequency in a temporal twoalternative forced-choice task. Spatial frequency discrimination thresholds were estimated using a staircase technique that controlled the value of $\Delta f$, which could range from $1 \%$ to $40 \%$ in increments of $1 \%$ of the reference spatial frequency. The same maximum likelihood algorithm described above was used to provide an estimate of the discrimination threshold, which was defined as the $75 \%$ correct performance level. The maximum likelihood estimation was determined for each of 40 trials, the estimate given after the 40th trial was defined as the threshold value.

\section{Results}

\section{Contrast sensitivity}

The results of the contrast detection threshold measurements are shown in Figure 2. The logarithm of the inverse of detection threshold, contrast sensitivity, is shown as a function of the spatial frequency (c/degree). Panel $a$ shows the results for the patients with left hemisphere damage, panel $b$ presents the results for the patients with right hemisphere damage, and panel $c$ shows the results for the control subjects. Open symbols present the results for measurements made for stimuli presented in the LVF, and solid symbols show the results for stimuli presented in the RVF. The mean values \pm 1 SEM are shown.

An ANOVA was performed on the logarithm of the contrast 


\begin{tabular}{|c|c|c|c|c|c|c|c|c|}
\hline $\begin{array}{l}\text { Patient } \\
\text { number }\end{array}$ & $\begin{array}{l}\text { Lesioned } \\
\text { side }\end{array}$ & $\begin{array}{l}\text { Age } \\
\text { (years) }\end{array}$ & Sex & Diagnosis & $\begin{array}{l}\text { Date of } \\
\text { surgery }\end{array}$ & $\begin{array}{l}\text { Symptoms prior } \\
\text { to surgery }\end{array}$ & $\begin{array}{l}\text { Symptoms at time } \\
\text { of study }\end{array}$ & $\begin{array}{l}\text { Medication at } \\
\text { time of study }\end{array}$ \\
\hline PAT01 & Left & 55 & Male & $\begin{array}{l}\text { Oligoastro- } \\
\text { cytoma } \\
\text { (WHO II) }\end{array}$ & 1.1990 & GM in 1989 & None & None \\
\hline РAT02 & Left & 57 & Female & Meningioma & 11.1990 & GM in 1990 & Mild recurrent vertigo & $\begin{array}{l}\text { Zentropil } \\
\text { (phenytoin) }\end{array}$ \\
\hline PAT03 & Left & 33 & Female & Cavernoma & 10.1988 & $\begin{array}{l}\text { Psychomotor seizures } \\
\text { since } 1975\end{array}$ & $4 \times \mathrm{GM}$ & $\begin{array}{l}\text { Timonil (car- } \\
\text { bamazapine) }\end{array}$ \\
\hline PAT04 & Left & 31 & Male & Cavernoma & 9.1988 & $\begin{array}{l}\text { Psychomotor seizures } \\
\text { since } 1974\end{array}$ & Recurrent nausea & Timonil \\
\hline PAT05 & Left & 35 & Male & Cavernoma & 2.1991 & Recurrent focal seizures & None & Zentropil \\
\hline PAT06 & Lcft & 50 & Malc & Cavcrnoma & 1.1987 & $\begin{array}{l}\text { Loss of consciousness and } \\
\text { chronic drowsiness in } \\
1986\end{array}$ & $\begin{array}{l}\text { Mild dysgraphia, easily } \\
\text { fatigued }\end{array}$ & None \\
\hline PAT07 & Left & 34 & Male & Cavernoma & 5.1987 & GM in 1986 & None & Timonil \\
\hline PAT08 & Left & 35 & Female & Cavernoma & 3.1990 & Gerstmann syndrome & $\begin{array}{l}\text { Transient mild dysnomia } \\
\text { and dysgraphia }\end{array}$ & Zentropil \\
\hline PAT09 & Left & 47 & Male & Cavernoma & 2.1988 & $\begin{array}{l}\text { Acute headache, } \\
\text { hemiparesis }\end{array}$ & None & Zentropil \\
\hline РAT10 & Left & 28 & Female & Cavernoma & 10.1985 & $\begin{array}{l}\text { GM in } 1985 \text {, recurrent } \\
\text { headache }\end{array}$ & $\begin{array}{l}\text { GM, } 3 \text { months } \\
\text { postoperative }\end{array}$ & $\begin{array}{l}\text { Tegretal (car- } \\
\text { bamazapine) }\end{array}$ \\
\hline PAT11 & Left & 40 & Female & Cavernoma & $\begin{array}{r}2.1991, \\
\text { preop }\end{array}$ & GM in 1986 & None & None \\
\hline PAT12 & Right & 49 & Female & Cavernoma & 10.1985 & $\begin{array}{l}2 \times \text { transient fluent } \\
\text { aphasia, agraphia }\end{array}$ & Sensory amusia & None \\
\hline PAT13 & Kight & 30 & Male & Cavernoma & 6.1984 & $\begin{array}{l}\text { Psychomotor epilepsy, } \\
\text { sensory amusia }\end{array}$ & Ca. 1 GM p.a. & $\begin{array}{r}\text { Mylepsinum } \\
\text { (primidon) }\end{array}$ \\
\hline PAT14 & Right & 58 & Male & $\begin{array}{l}\text { Ischemic } \\
\text { insult }\end{array}$ & $\begin{array}{r}(1986) \text { not } \\
\text { operated }\end{array}$ & GM in 1984 & None & $\begin{array}{l}\text { Timonil, phen- } \\
\text { emal (pheno- } \\
\text { barbital) }\end{array}$ \\
\hline PAT 15 & Right & 38 & Female & Cavernoma & 11.1986 & Repeated GM since 1980 & None & None \\
\hline PAT16 & Right & 30 & Male & Cavernoma & 9.1988 & $4 \times$ GM in 1988 & None & Zentropil \\
\hline PAT17 & Right & 19 & Male & $\begin{array}{l}\text { Astrocytoma } \\
\text { (WHO II) }\end{array}$ & 7.1986 & Complex focal seizures & Complex focal seizures & Zentropil \\
\hline
\end{tabular}

sensitivity values, which tested the effects of the between-subjects factor of group (i.e., patients vs controls), and the withinsubjects factors of visual field and spatial frequency. There was a significant effect of spatial frequency on log contrast sensitivity $\left(F_{2,62}=118.1, p<0.001\right)$, which is in accordance with the literature (Campbell and Robson, 1968). For the $4^{\circ}$ eccentric fixation used, sensitivity was greatest for the 2.5 and $5 \mathrm{c} /$ degree stimuli, and declined rapidly for the $10 \mathrm{c} /$ degree targets. There was a marginally significant effect of visual field $\left(F_{1,31}=4.52, p\right.$ $<0.05$ ), where sensitivity to stimuli presented in the LVF was slightly higher. The effect of group was not significant $\left(F_{2,31}=\right.$ 0.56 , NS). This absence of a group difference indicates that the patients did not differ from the age-matched control subjects with respect to their ability to detect the eccentrically presented grating stimuli.

\section{Spatial frequency discrimination thresholds}

The results of the spatial frequency discrimination task are shown in Figure 3. The columns show the mean discrimination threshold \pm 1 SEM for the three groups, averaged over the three ISI conditions, separately for stimuli presented in each hemifield. Open columns present the results for stimuli presented in the
LVF, and shaded columns show the findings for stimuli presented in the RVF. Discrimination thresholds are elevated in the patients, and this elevation is more pronounced in the visual hemifield contralateral to the damaged hemisphere.

Figure 4 presents these same findings as a function of the ISI interval. Panel $a$ shows the findings for patients with left temporal lobe lesions, panel $b$ gives the results for patients with right temporal lobe damage, and panel $c$ presents the findings from the control subjects. Open symbols give thresholds for stimuli presented in the LVF, and solid symbols show the results for RVF presentation. Again, discrimination thresholds are significantly elevated in the patients, and this elevation is more pronounced in the hemifield contralateral to the side of the cerebral lesion.

An ANOVA was performed on the spatial frequency discrimination threshold values, which tested the effects of the betweensubjects factor of group, and the within-subjects factors of visual field and ISI. This analysis revealed a highly significant effect of group on the frequency discrimination thresholds $\left(F_{2,31}=\right.$ $7.77, p<0.002$ ), indicating that the patients with temporal lobe damage had significantly higher thresholds than the age-matched control subjects. There is also a significant interaction between 

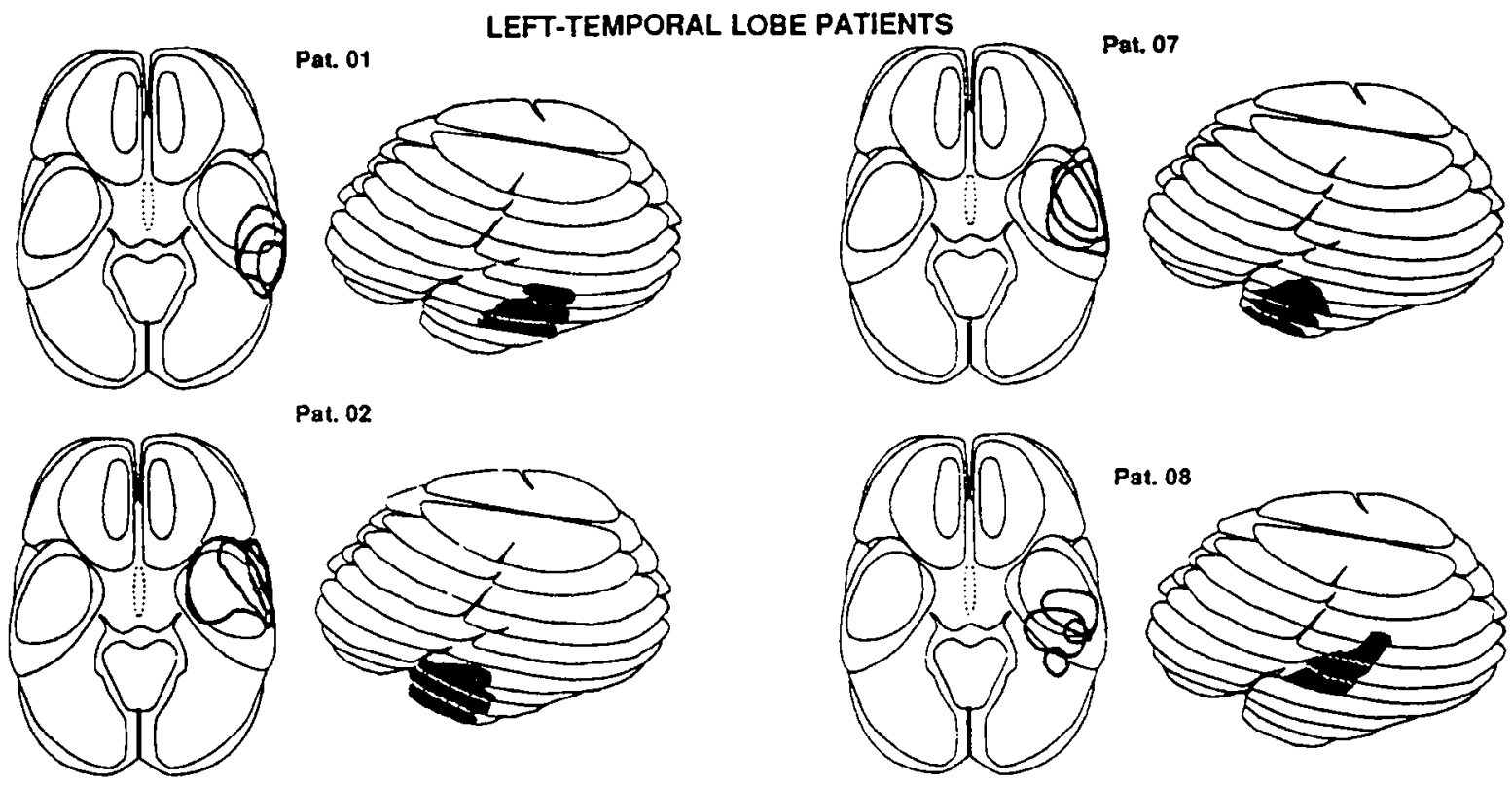

Pat. 02
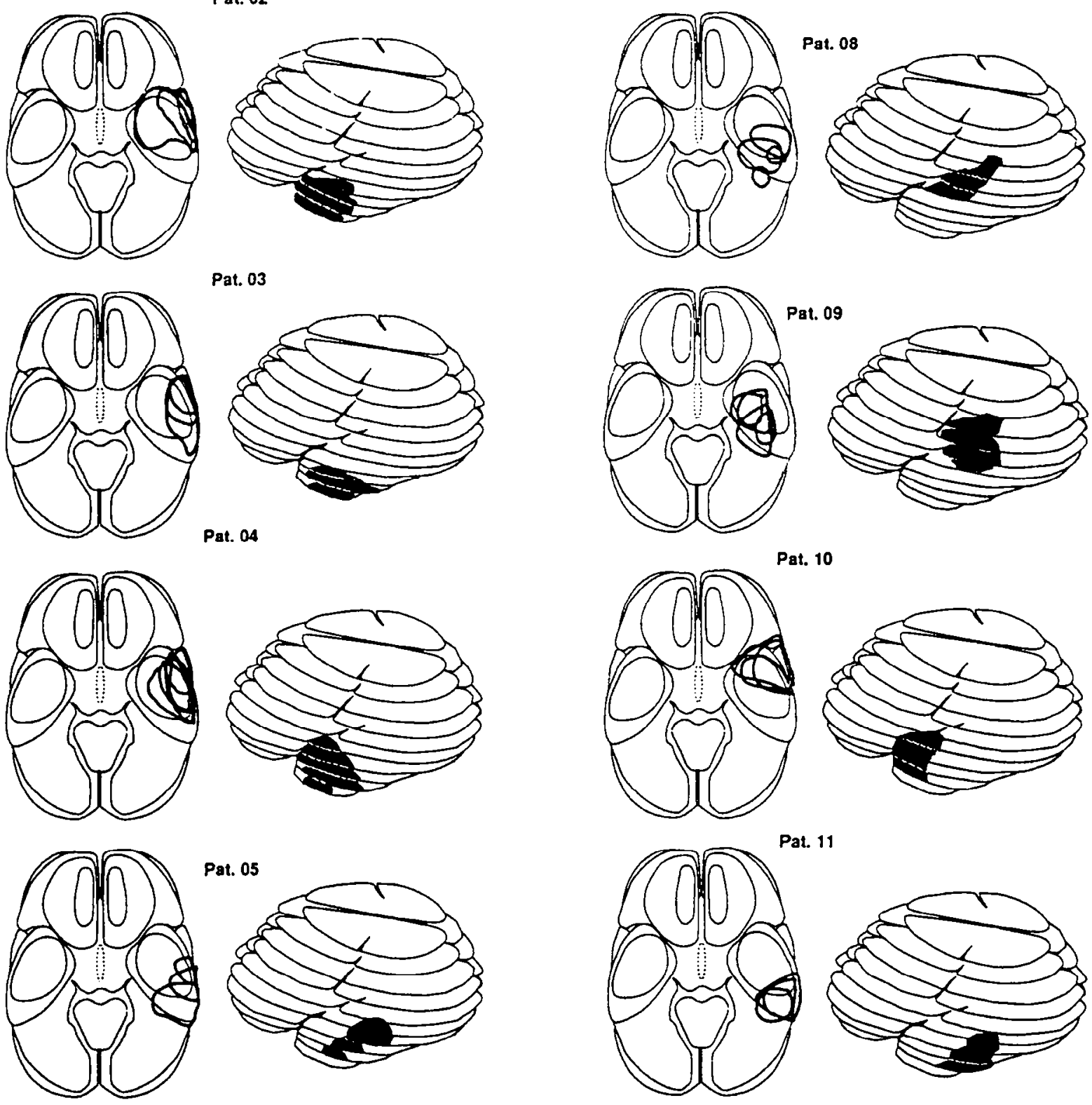

Pat. 05
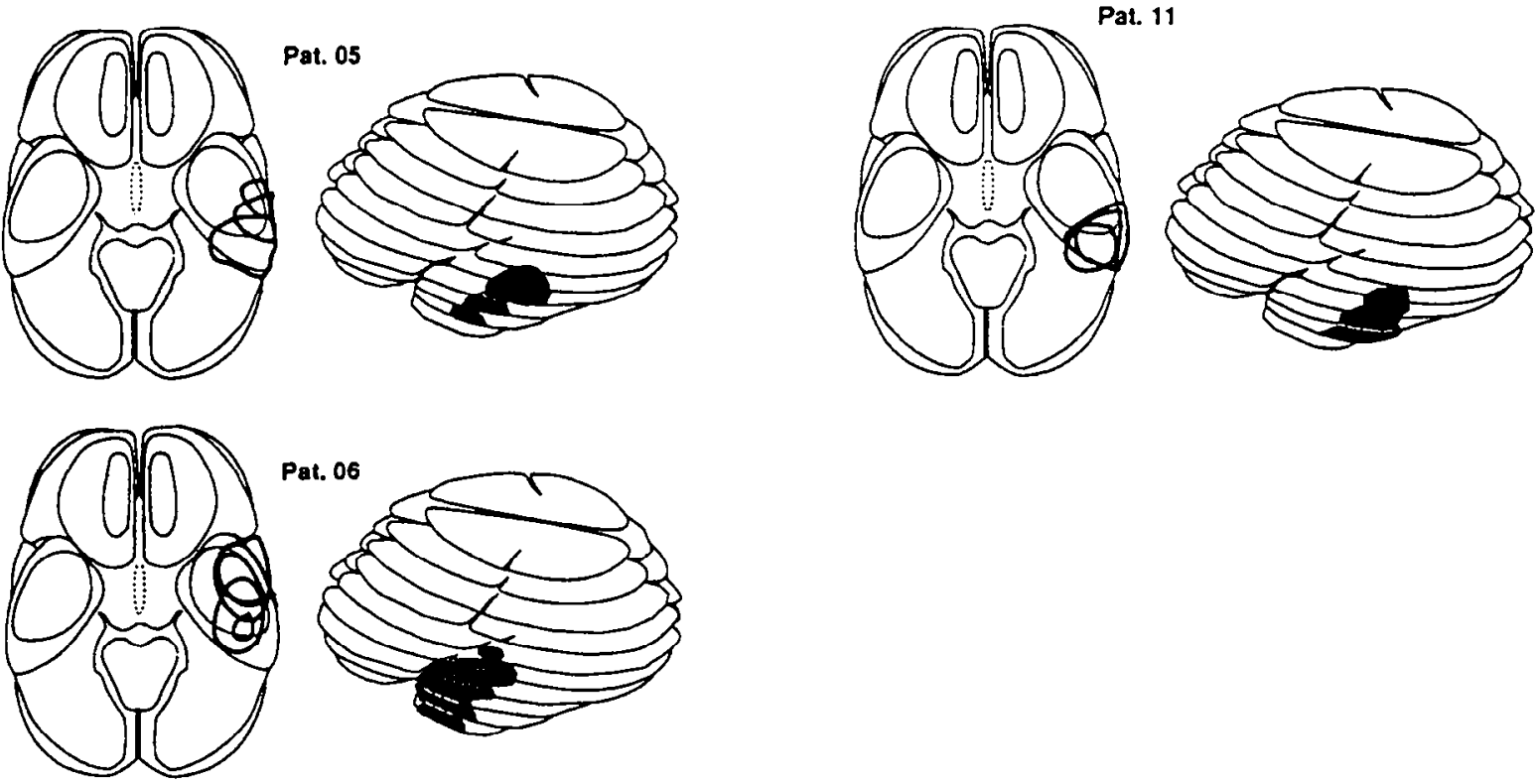
RIGHT-TEMPORAL LOBE PATENTS
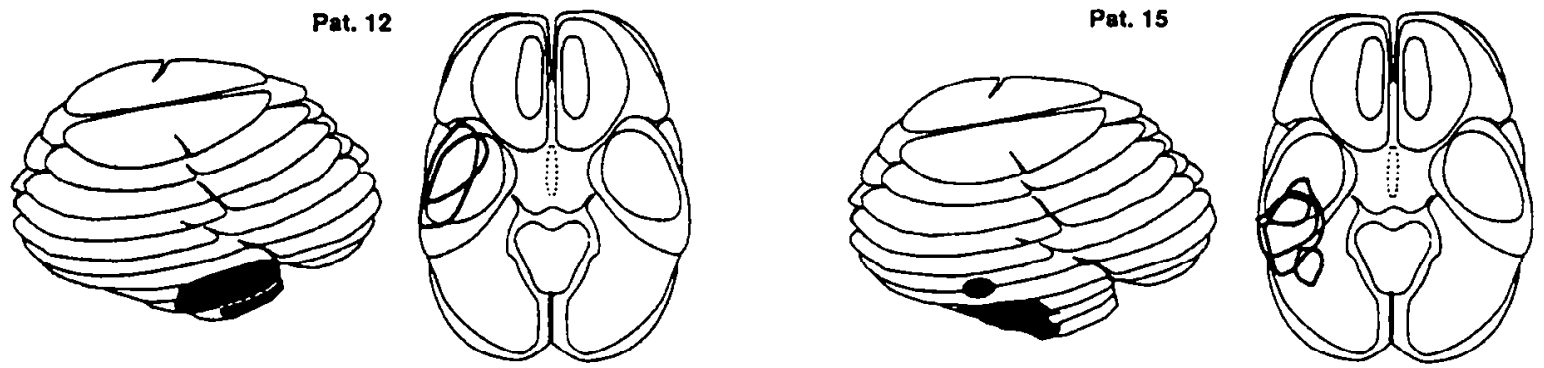

Pat. 13
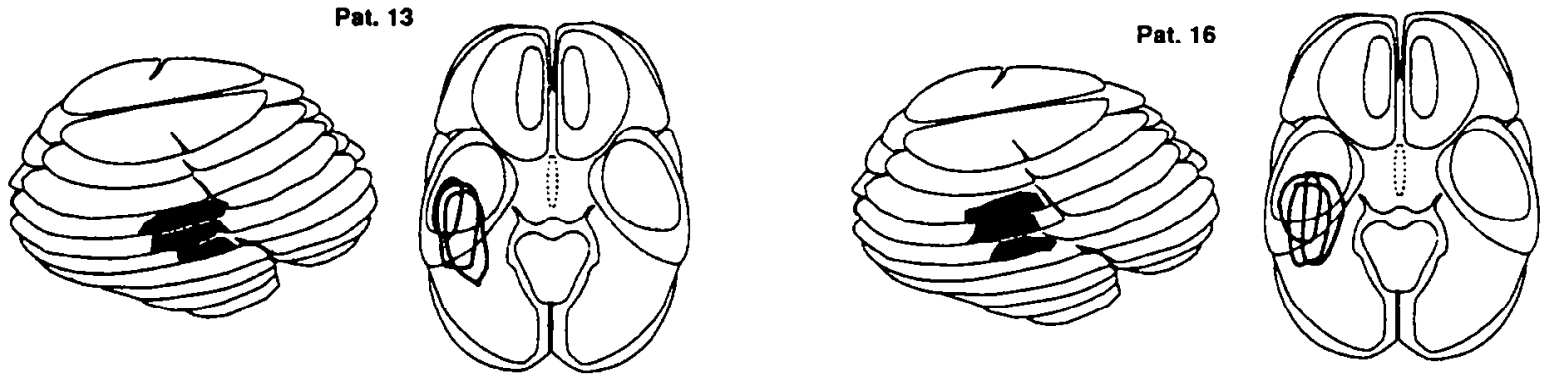

Pat. 14
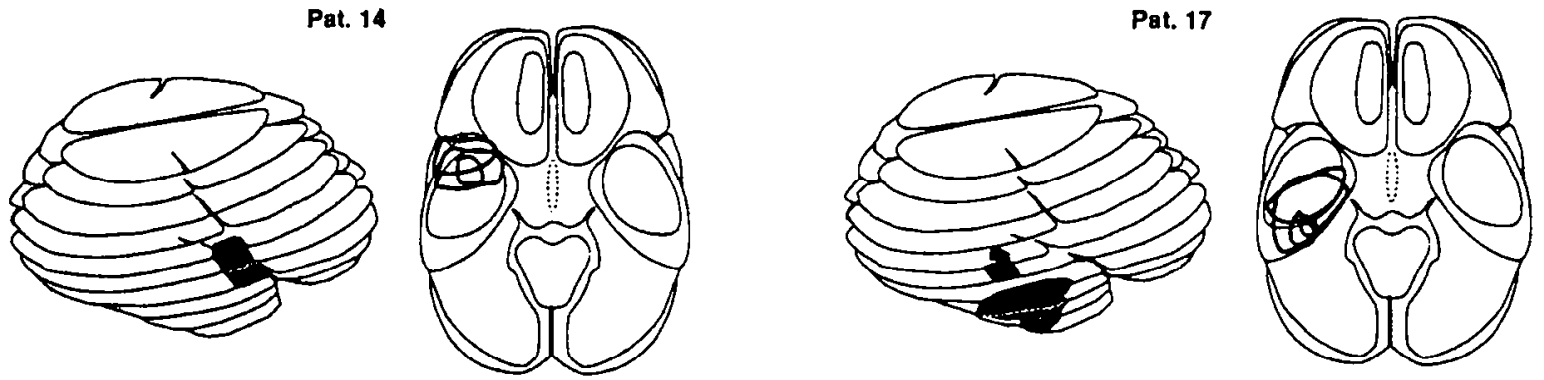

Figure 1. Schematic representation of the computed tomograms of 11 patients with a lesion in the left temporal lobe (Pat. 0I-Pat. 11 ) and 6 patients with a lesion in the right temporal lobe (Pat. 12-Pat. 17).

the main effects of group and visual field on discrimination thresholds $\left(F_{2,31}=7.72, p<0.002\right)$. In the control subjects discrimination thresholds are slightly lower for stimuli presented in the RVF. This pattern holds up for all three ISI conditions. This same lateral difference is evident in the patients with damage to the right temporal lobe (middle columns), however, with the differences being more pronounced. The pattern reverses for the patients with damage to the left temporal lobe: discrimination thresholds are higher for stimuli presented in the RVF. a) Left Hemisphere patients $(n=11)$

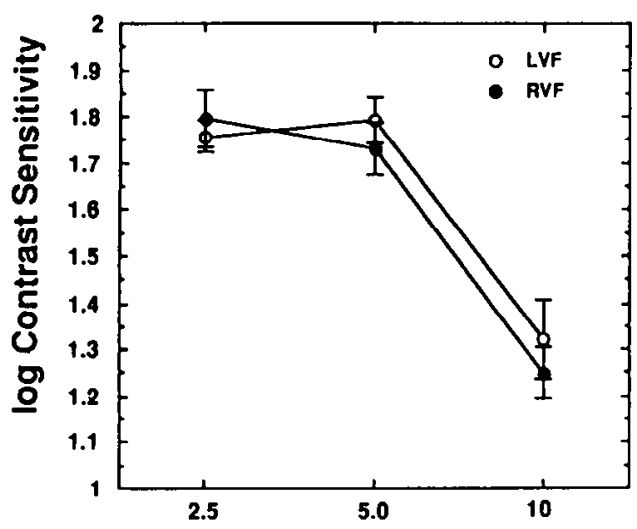

Spatial Frequency (c/deg) b) Right Hemisphere patients $(n=6)$

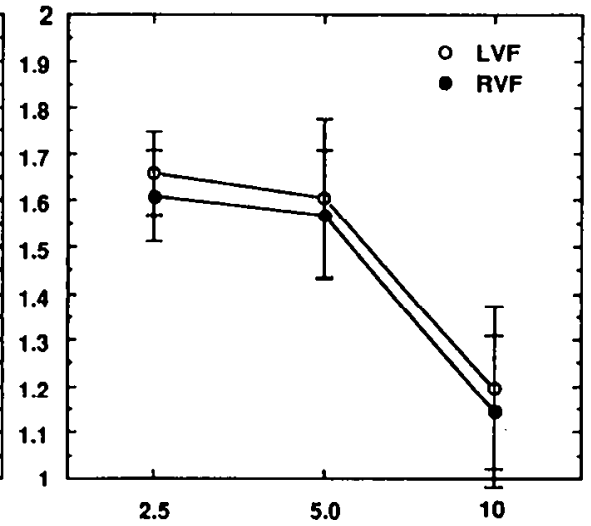

Spatial Frequency (c/deg) c) Control Subjects $(n=17)$

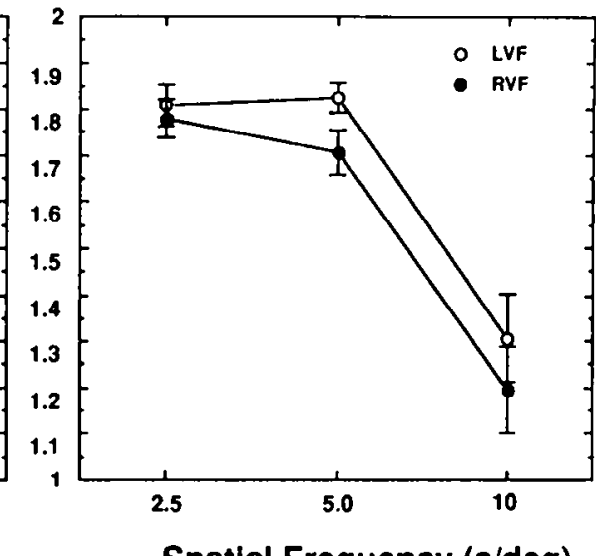

Spatial Frequency (c/deg)

Figure 2. Mean log contrast sensitivity for sinusoidal grating patches presented in the LVF (open symbols) and RVF (solid symbols) as a function of spatial frequency for patients with left temporal lobe damage $(a)$, patients with right temporal lobe damage $(b)$, and age-matched control subjects (c). The gratings were presented for $700 \mathrm{msec}, 4^{\circ}$ to the right or left of a central fixation point. 


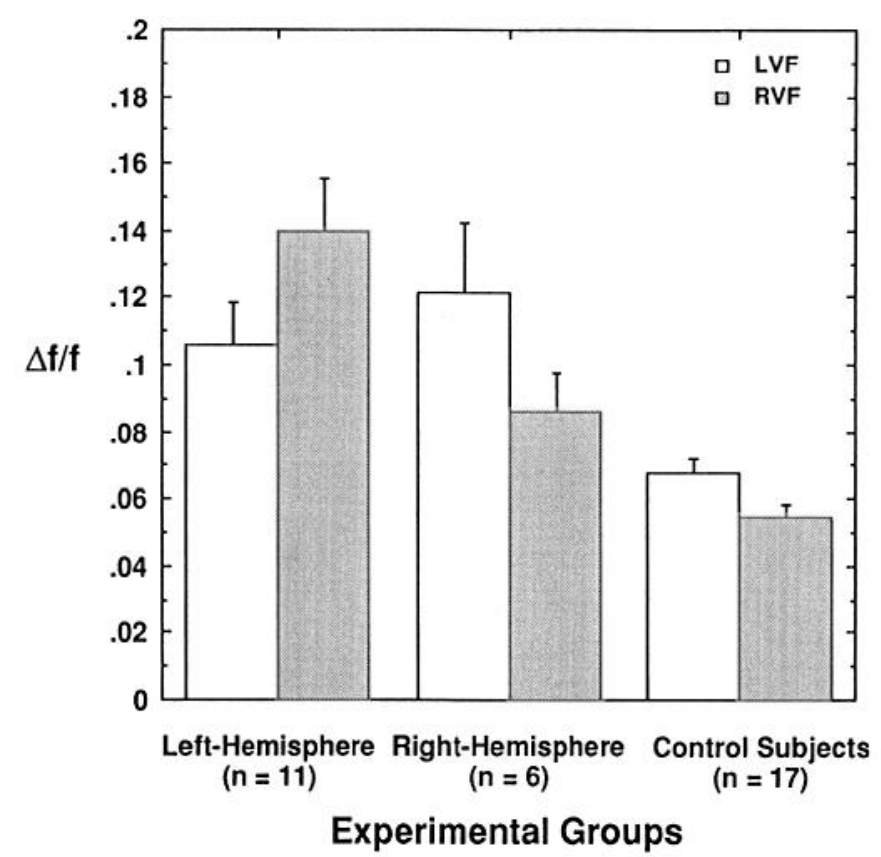

Figure 3. Mean spatial frequency discrimination thresholds for stimuli sequentially presented in the LVF (open columns) and RVF (shaded columns) plus 1 SEM. The results are shown separately for the 11 patients with damage to the left temporal lobe (leftmost columns), 6 patients with right temporal lobe damage (middle columns,) and 17 agematched control subjects (rightmost columns).

\section{Region of interest and effect of ISI on discrimination thresholds}

The patients were divided into two groups depending on whether the lesion extended into the IT lobe or was outside the IT lobe. The region-of-interest group comprised 10 patients ( 7 left hemisphere, 3 right hemisphere), while the non-region-of-interest group was made up of 7 patients (4 left hemisphere, 3 right hemisphere). In Figure 5 we compared spatial frequency discrimination thresholds as a function of the ISI for the regionof-interest group $(a)$ to those measured in the non-region-of- interest group $(b)$. Discrimination thresholds for stimuli presented in the visual field ipsilateral to the damaged hemisphere are shown by open symbols, and thresholds for stimuli presented in the contralateral visual field are given by solid symbols. For sake of comparison, the results of the control subjects are taken from Figure 4 and are shown again in of Figure $5 c$. An ANOVA revealed a significant main effect of visual field relative to damaged hemisphere (i.e., ipsi-, contralateral; $F_{1,15}=8.67, p=0.01$ ), in which discrimination thresholds for stimuli presented in the visual field contralateral to the damaged hemisphere were, on average, $35 \%$ higher than those measured in the ipsilateral visual field. The main effects of lesion location and ISI were not significant. The interaction between these latter factors $\left(F_{2,30}=\right.$ $1.82, p<0.18$ ), though not significant, suggested that there was a tendency for the IT patients to exhibit higher thresholds with increasing ISI.

Post hoc paired comparisons revealed a significant difference between thresholds measured in the contralateral visual field for the short (ISI $=1$ or $3 \mathrm{sec}$ ) versus long (ISI = $10 \mathrm{sec}$ ) ISIs ( $3 \mathrm{sec}$ ISI vs $10 \mathrm{sec}$ ISI, $t=2.85, p=0.01$ ) in the patients with damage to the IT cortex (Fig. $5 a$ ). These differences were not significant in the non-region-of-interest group. Although the IT patients exhibit the highest thresholds for stimuli presented in the contralateral visual field with a $10 \mathrm{sec}$ delay, due to the large variability among these 10 patients, this value is not significantly different from that measured in the patients with medial-superior temporal lobe lesion (mean $\Delta f / f=0.176 \pm 0.039$ vs $\left.0.107 \pm 0.01 ; F_{1,15}=2.1, p<0.18\right)$.

\section{Effect of age on contrast sensitivity and discrimination thresholds}

As there was a fairly large age range in our patient and control group, we could examine the relationship between age and contrast sensitivity, as well as between age and spatial frequency discrimination thresholds. The results of the ANOVA indicate that the observers' age had a highly significant effect on log sensitivity $\left(F_{1,30}=9.54, p<0.005\right)$, and that age interacted with stimulus spatial frequency $\left(F_{2,60}=15.5, p<0.0001\right)$ in determining log sensitivity. The regression of log contrast sensitivity on age is shown for both patient and subject groups in Figure a)

Left-Hemisphere Patients $(n=11)$

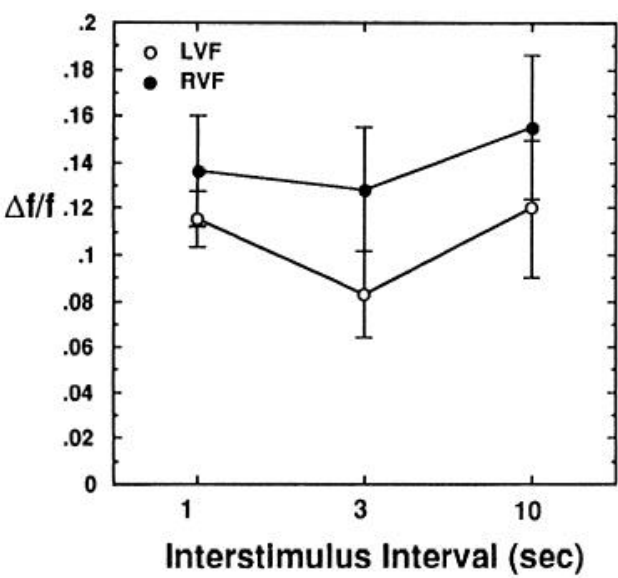

b)

Right-Hemisphere Patients ( $n=6$ )

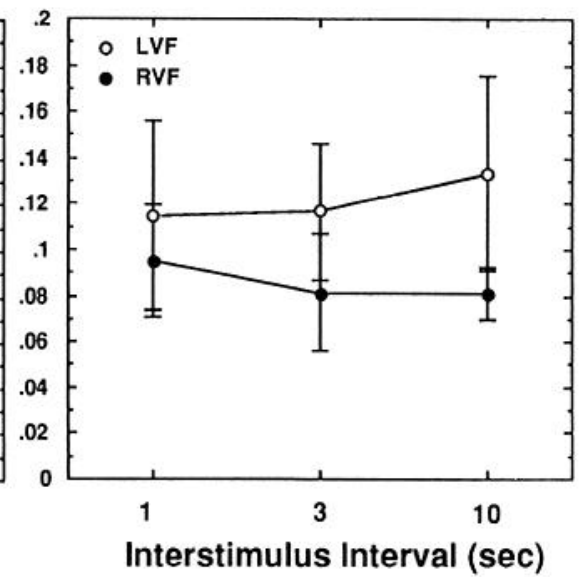

C) Control subjects $(n=17)$

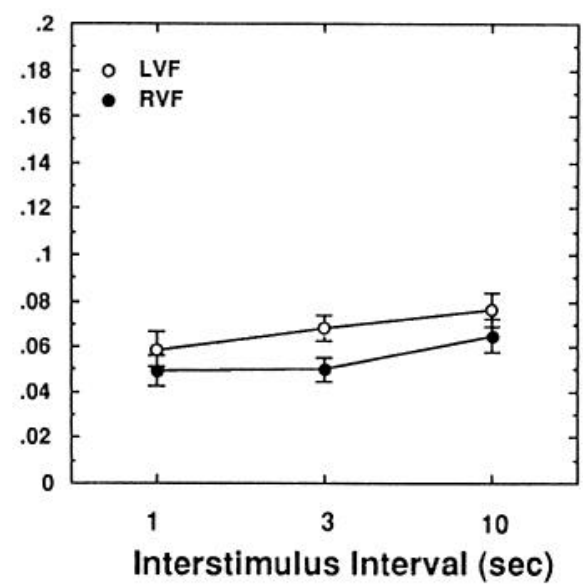

Figure 4. Mean spatial frequency discrimination thresholds \pm 1 SE as a function of the ISI for patients with left temporal lobe damage (a), patients with right temporal lobe damage $(b)$, and age-matched control subjects $(c)$. Results for stimuli presented in the LVF are shown by open symbols; those for the RVF, by solid symbols. 
a)

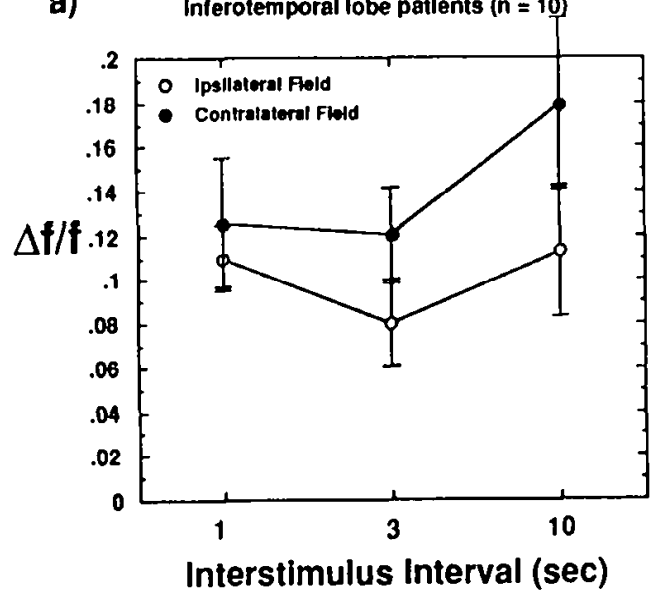

b) medlal-superlor temporal lobe patlents $(n=7)$

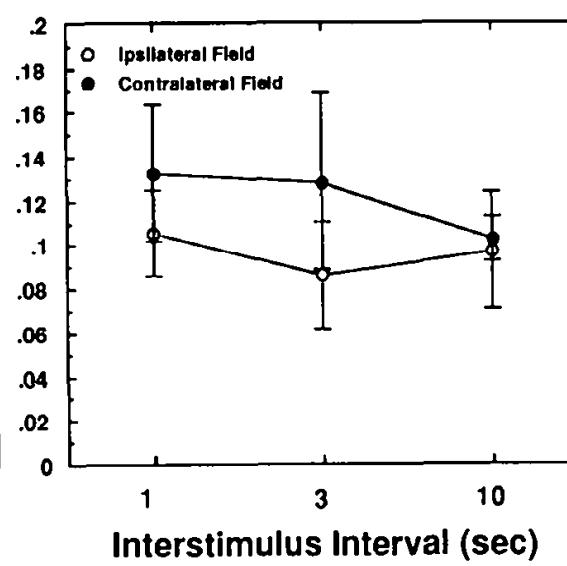

control subjects $(n=17)$

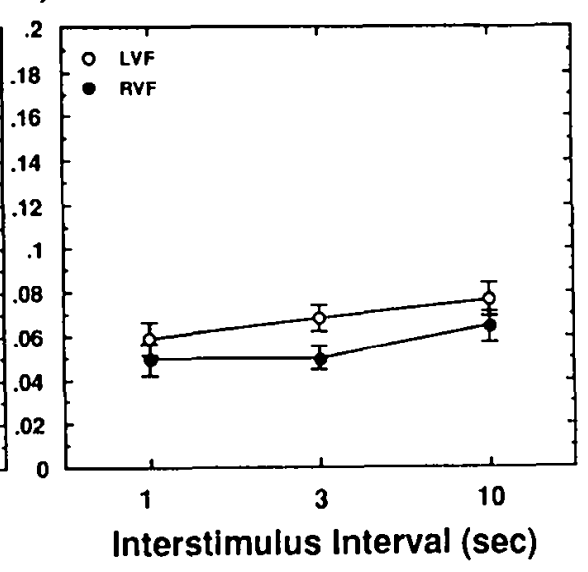

Figure 5. Mean spatial frequency discrimination thresholds as a function of the ISI for patients with II lobe damage (a), patients with medialsuperior temporal lobe damage $(b)$, and age-matched control subjects $(c)$ (repeated from Fig. $4 c$ ). Results for stimuli presented in the visual field ipsilateral to the damage hemisphere are shown by open symbols; those for the contralateral visual field, by solid symbols (patients only).

6 for the three spatial frequencies tested. In support of earlier work (Owsley et al., 1983; Higgins et al., 1988; Elliott et al., 1990; Werner et al., 1990), there is a correlation between log contrast sensitivity and age, and this correlation is significant for higher spatial frequencies.

On the contrary, our analysis revealed no significant correlation between age and the spatial frequency discrimination thresholds. This absence of effect, in part, is a consequence of adjusting test contrast to be a constant factor above threshold for each observer. This manipulation would act to nullify the effect of the reduced contrast sensitivity with increasing age on discrimination thresholds. If, however, the subjects' age is introduced as a continuous variable into the ANOVA, then there is a marginally significant interaction with the effect of ISI $\left(F_{2,60}\right.$ $=2.98, p<0.06$ ). A post hoc analysis revealed a significant correlation betwecn the increase in discrimination thresholds when increasing the ISI from 3 to $10 \mathrm{sec}$ and observers' age $(r$ $=0.49, p<0.004$ ).

\section{Discussion}

The present results provide strong support for a role of the lower medial and IT cortex in the visual processing required for the delayed spatial frequency discrimination of sinusoidal gratings by human subjects. The results cannot be explained by reduced contrast sensitivity for these patterns, since contrast sensitivity was not significantly reduced in the patients (Fig. 2). We also controlled for the effects of reduced contrast sensitivity by adjusting the contrast of the grating stimuli used in the discrimination task to be a constant factor of 5 above the individual detection thresholds. For this suprathreshold contrast value, test contrast ceases to have a significant effect on discrimination thresholds in healthy subjects (Thomas, 1983; Greenlee, 1992). There was also no overall statistically significant effect of age on spatial frequency discrimination thresholds, although there was a significant correlation between age and contrast sensitivity. The absencc of a direct relationship between age and frequency discrimination performance further confirms that our manipulation of suprathreshold contrast was successful in controlling for any spurious effects sensitivity might have had on discrimination performance.
Spatial frequency discrimination thresholds for sequentially presented stimuli were significantly elevated in the patients with temporal lobe damage, and this effect was more pronounced for the visual field contralateral to the damaged hemisphere (Fig. 3). However, discrimination thresholds were also significantly elevated for stimuli presented in the visual field ipsilateral to the damaged hemisphere. Although we cannot rulc out the possible effects of antiepileptic medication, this finding suggests a bilateral impairment in the ability of these patients to perform the delayed spatial frequency discrimination task. Such a spread of impairment in discrimination performance to both visual ficlds is in agreement with the obscrvation that the receptive fields of IT cortical cells in the nonhuman primate are large $\left(20^{\circ}\right.$ in diameter and larger) and often extend across the vertical central meridian (Gross et al., 1972; Desimone and Gross, 1979). It should also be noted here that discrimination thresholds were elevated in the patients even for the shortest ISI used, and thresholds only increased moderately for the longer ISIs (Figs. 4,5 ). This latter observation suggests that the patients' ability to recognize two sequentially presented stimuli as different is impaired even for very short delays.

We chose to use a spatial frequency in the medium spatial frequency range $(5 \mathrm{c} /$ degrec $)$ and measured sensitivity at that spatial frequency and at frequencies \pm 1 octave away from it. Discriminations for spatial frequencies at and near $5 \mathrm{c} /$ degree can be as low as $2 \%$ in foveal vision and increase with increasing eccentricity. The values found in the healthy control subjects in the present study are remarkably similar to those found in our laboratory for trained subjects under similar conditions (Greenlee, 1992). As both control and patient groups performed these psychophysical tasks for the first time, the similarity of the results between trained and untrained observers suggests that the effects of training on performance in this task are minimal.

Among the 17 patients studied, 10 patients had lesions that were primarily located in the IT cortex, whereas 7 patients showed lesions that were located in medial and/or superior temporal cortex. We explored the possible effect of the ISI on discrimination thresholds after dividing these patients into two groups based on the location of the cerebral lesion. This post hoc analysis revealed a significant effect of ISI on spatial frequency dis- 

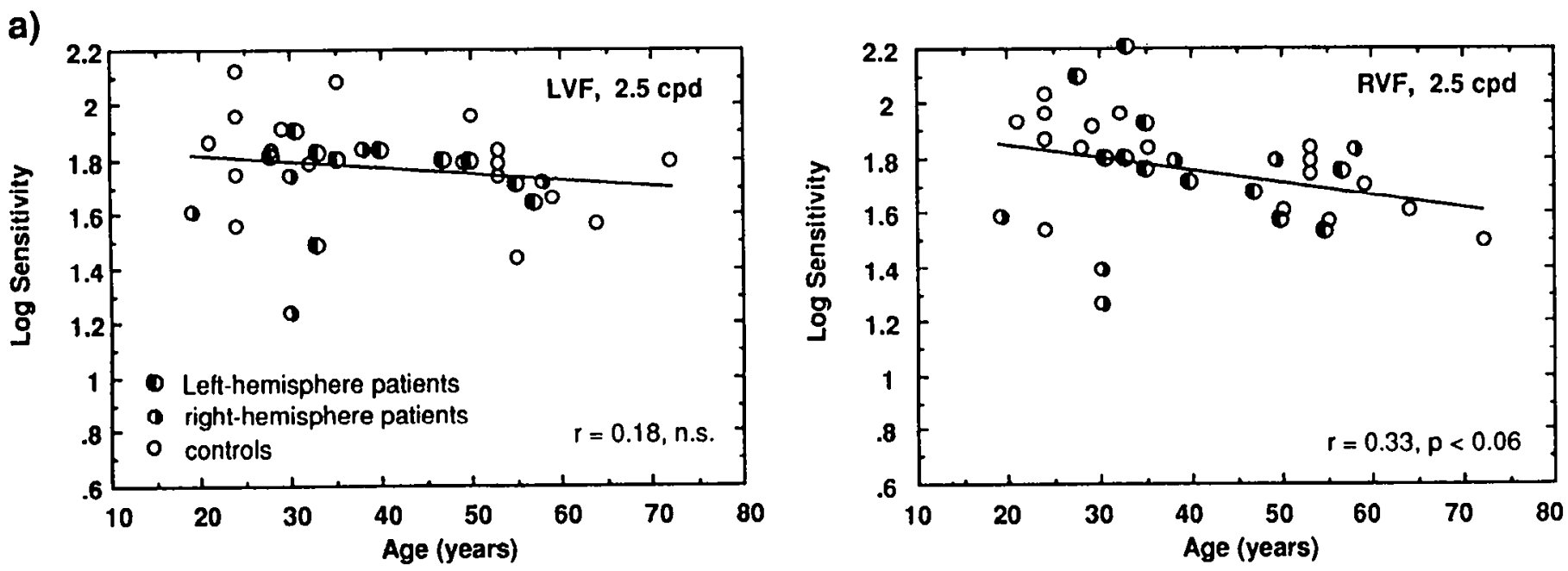

b)
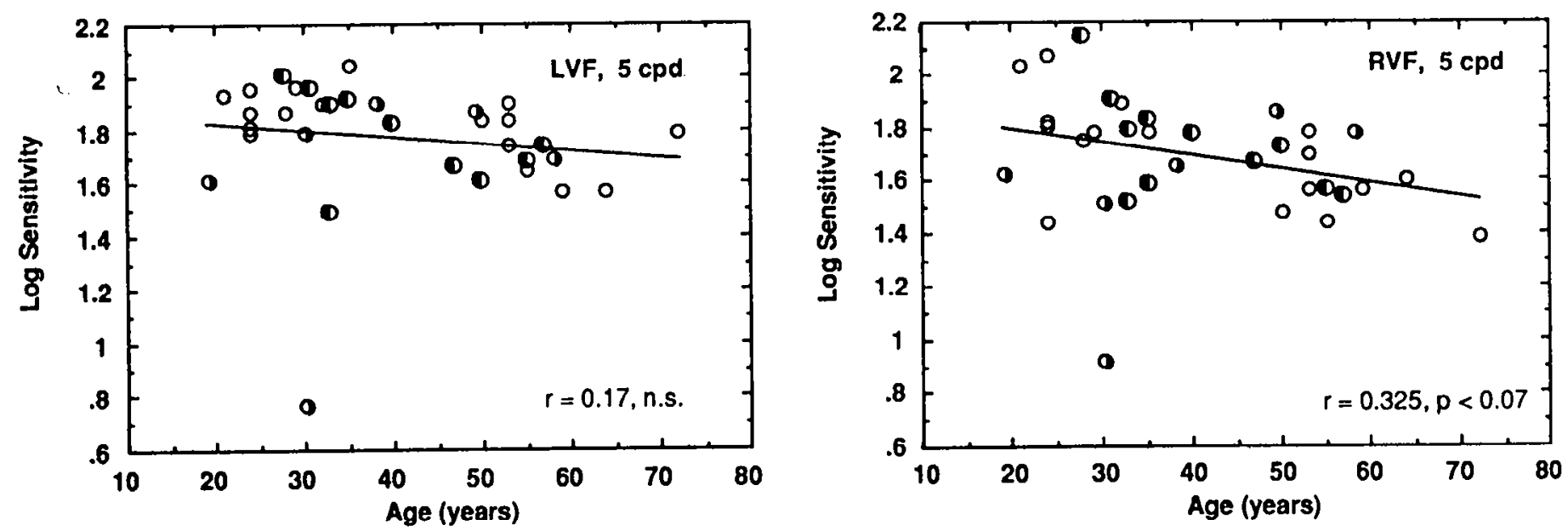

c)
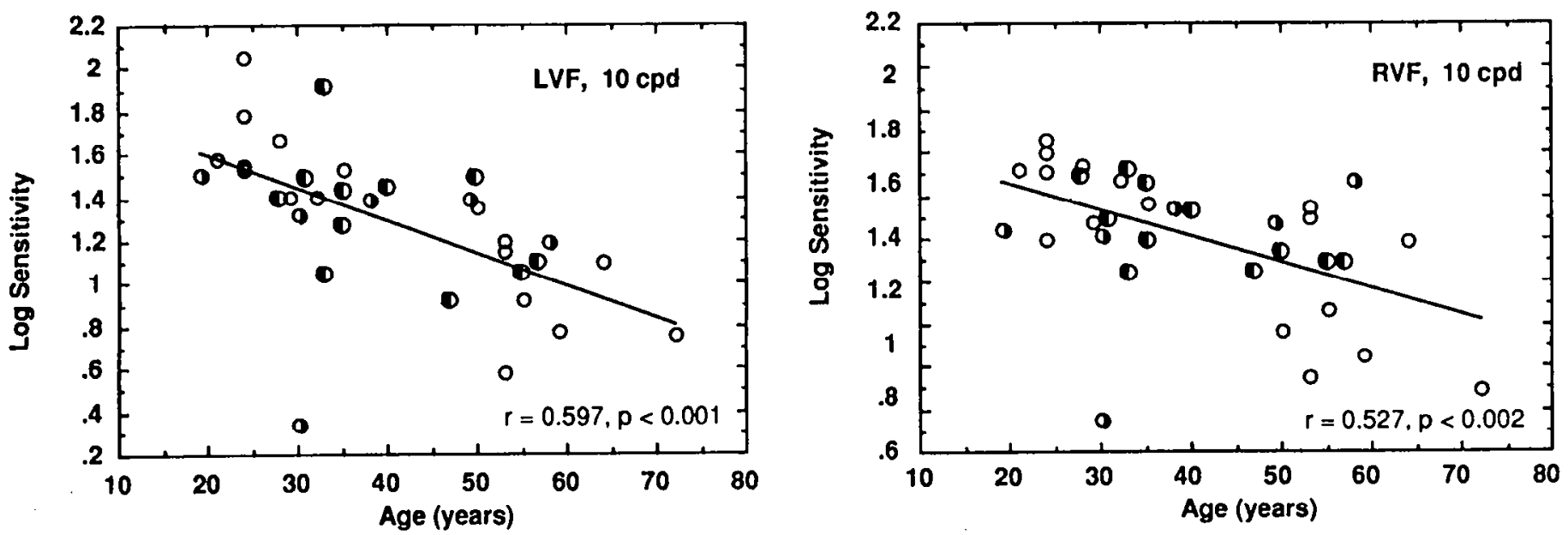

Figure 6. Log contrast sensitivity averaged over LVF and RVF presentations for all 34 subjects as a function of the subjects' age. The upper two panels $(a)$ present the results for the $2.5 \mathrm{c} /$ degree grating stimuli, the middle panels $(b)$ show the findings for the $5.0 \mathrm{c} /$ degree gratings, and the lower panels $(c)$ present the results for the $10.0 \mathrm{c}$ /degree gratings. Open symbols give the results of the 17 control subjects and semisolid symbols show the results of the patients. 
crimination thresholds for stimuli presented in the visual field contralateral to the damaged hemisphere in patients with IT lesions. This effect was absent in patients with medial-superior temporal lobe damage. We interpret this pattern of results as support for the idea that the IT cortex is involved in the shortterm storage of spatial frequency information. However, the differences between the patients with IT lesions and the patients with lesions in medial-superior temporal cortex were not significant. This lack of significance is in part due to the greater amount of scatter in the threshold values for the patients with IT lesions, but also suggests that other visual areas in the temporal lobe are involved in the processes underlying recognition memory.

It could be argued that the lesions in the patients studied herc not only affect the temporal cortex, but protrude deep into the white matter and thus could affect fibers of passage as well as temporal-frontal connections. Careful analysis of the computed tomograms and magnetic resonance images ruled out substantial inclusion of the white matter in most of the lesions in our patients. We also took care to exclude patients whose lesions involved the hippocampus or the perirhinal and rhinal cortex. As these cortical and subcortical areas have been implicated in human memory, damage to these areas would possibly lead to a general memory decline, which would not be specific to visual memory. It remains to be determined whether delayed discrimination is also impaired in these patients for other sensory modalities like audition.

In healthy human observers, Magnussen and coworkers (Magnussen et al., 1990, 1991) have recently demonstrated that spatial frequency information can be stored in visual memory with perfect accuracy for periods up to $10 \mathrm{sec}$. This perfect storage of spatial frequency information can, however, be disturbed by introducing a "memory masker" during the retention interval (Magnussen et al., 1991). Interestingly, the memory masking effect was greatest for maskers differing along the dimension to be discriminated (i.e., spatial frequency), but was ncgligible for maskers differing along another dimension (i.e., orientation). These results suggest a form of visual memory storage, in which the basic stimulus dimensions of spatial frequency, orientation, color, contrast, and so on, are stored in separate memory arrays. Stimulus-specific memory masking suggests that elements interfere with each other within but not across arrays. The present results in patients with damage to the temporal cortex suggest that such lesions disrupt the neural processes normally underlying the visual representation of such an elementary stimulus dimension as spatial frequency. Further investigations should explore possible deficits in the processing of other fundamental stimulus dimensions such as orientation and stimulus motion.

The observers' age had a significant effect on contrast sensitivity, especially for the highest spatial frequency tested (10 c/degree; compare Fig. 6). There was no significant correlation between age and the spatial frequency discrimination thresholds. The observers age, however, did contribute to accounting for some of the variance in the spatial frequency discrimination thresholds by significantly interacting with the effect of the ISI. This significant interaction suggests that the general effects of aging might act, in part, to impair visual memory for simple spatial attributes. Further study in larger subject samples would be required to substantiate such an implication.

In summary, the present findings suggest that the human IT cortex is involved in the processing of the spatial frequency of visual stimuli. The outputs of neurons in areas V1 and V2 in the visual cortex, and V4 in extrastriate cortex, which have receptive fields selective to the spatial frequency and orientation of visual stimuli, are stored and compared in higher visual areas in the temporal cortex. Our findings indicate that the impairment in discrimination performance was more pronounced in the visual field contralateral to the damaged hemisphere. These results provide experimental evidence for a role of the human IT cortex in the sequential processing of a stimulus dimension fundamental to the analysis of complex visual images.

\section{References}

Britten KH, Newsome WT, Saunders RC (1992) Effect of inferotemporal cortex lesions of form-from-motion discrimination in monkeys. Exp Brain Res 88:292-302.

Campbell FW, Robson JG (1968) Application of Fourier analysis to the visibility of gratings. J Physiol (Lond) 197:551-566.

Corbetta M, Miezin FM, Dobmeyer S, Shulman GL, Petersen SE (1991) Selective and divided attention during visual discriminations of shape, color and speed: functional anatomy by positron emission tomography. J Neurosci 11:2383-2402.

Cowey A, Gross CG (1970) Effects of foveal prestriate and inferotemporal lesions on visual discrimination by rhesus monkeys. Exp Brain Res 11:128-144.

Damasio AR, Damasio H, Van Hoesen GW (1982) Prosopagnosia: anatomical basis and behavioral mechanisms. Neurology 32:331341.

De Valois RL, De Valois KK (1988) Spatial vision. New York: Oxford UP.

Dean P (1976) Effects of inferotemporal lesions on the behavior of monkeys. Psychol Bull 83:41-71.

Desimone R, Gross CG (1979) Visual areas in the temporal cortex of the macaque. Brain Res 178:363-380.

Desimone R, Albright TD, Gross CG, Brucc C (1984) Stimulus selective properties of inferior temporal neurons in the macaque. $J$ Neurosci 4:2051-2062.

Elliott D, Whitaker D, MacVeigh D (1990) Neural contribution to spatiotemporal contrast sensitivity decline in healthy ageing eyes. Vision Res 30:541-547.

Fuster JM, Bauer RH, Jervey JP (1981) Effects of cooling inferotemporal cortex on performance of visual memory tasks. Exp Neurol 71: 398-409.

Greenlec MW (1992) Spatial frequency discrimination of band-limited periodic targets: effects of stimulus contrast, bandwidth and retinal eccentricity. Vision Res 32:275-283.

Gross CG, Rocha-Miranda CE, Bender DB (1972) Visual properties of neurons in inferotemporal cortex of the macaque. J Neurophysiol 35:96-111.

Haenny PE, Schiller PH (1988) State dependent activity in monkey visual cortex. I. Single cell activity in V 1 and V4 on visual tasks. Exp Brain Res 69:225-244.

Haenny PE, Maunsell JHR, Schiller PH (1988) State dependent activity in monkey visual cortex. II. Retinal and extraretinal factors in V4. Exp Brain Res 69:245-259.

Higgins KE, Jaffe MJ, Caruso RC, deMonasterio FM (1988) Spatial contrast sensitivity: effects of age, test-retest, and psychophysical method. J Opt Soc Am [A] 5:2173-2180.

Horel JA, Pytko-Joiner DE, Voytko ML, Salsbury K (1987) The performance of visual tasks while segments of the inferotemporal cortex are suppressed by cold. Behav Brain Res 23:29-42.

Kimura D (1963) Right temporal-lobe damage. Arch Neurol 8:264271.

Lieberman H, Pentland AP (1982) Microcomputer-based estimation of psychophysical thresholds: the best PEST. Behav Res Methods Instrum Comput 14:21-25.

Magnussen S, Greenlee MW, Asplund R, Dyrnes S (1990) Perfect visual short-term memory for periodic patterns. Eur J Cognit Psychol $2: 345-362$.

Magnussen S, Greenlee MW, Asplund R, Dyrnes S (1991) Stimulusspecific mechanisms of visual short-term memory. Vision Res 31: 1213-1219.

Marcelja S (1980) Mathematical description of the responses of simple cortical cells. J Opt Soc Am 70:1297-1300. 
Mikami A, Kubota K (1980) Inferotemporal neuron activitics and color discrimination with delay. Brain Res 182:65-78.

Miller EK, Li L, Desimone R (1991) A neural mechanism for working and recognition memory in inferior temporal cortex. Science 254: $1377-1379$.

Milner B (1968) Visual recognition and recall after right temporallobe excision in man. Neuropsychologia 6:191-209.

Milner B (1971) Interhemispheric differences in the localisation of psychological processes in man. Br Med Bull 27:272-277.

Mishkin M, Pribram KH (1954) Visual discrimination performance following partial ablations of the temporal lobe. I. Ventral and lateral. J Comp Physiol Psychol 47:14-20.

Mi Jashita Y, Chang HS (1988) Neuronal correlate of pictoral shortterm memory in the primate temporal cortex. Nature 331:68-70.

Nadjmi M, Piepgrass U, Vogelsang H (1991) Kranielle Computertomographie. Stuttgart: Thieme.

Owsley C, Sekuler R, Siemsen D (1983) Contrast sensitivity throughout adulthood. Vision Res 23:689-699.

Parrett DI, Rolls ET, Cann W (1982) Visual neurones responsive to faces in the monkey temporal cortex. Exp Brain Res 47:329-342.

Plant GT, Nakayama K (1992) Impaired motion perception following unilateral occipital damage. Invest Ophthalmol [Suppl] 32:824.

Roland PE, Widen L (1988) Quantitative measurement of brain metabolism during physiological stimulation. In: Functional brain imaging (Pfurtscheller G, de Silva FHL, eds), pp 213-228. Toronto: Huber.
Sahgal A, Hutchison R, Hughes RP, Iversen SD (1983) The effects of inferotemporal cortex lesions on Konorski delayed pair comparison in monkeys. Behav Brain Res 8:361-373.

Saito T, Isono, Yasuda, Mikami (1989) Directional selective response of cells in the middle temporal area (MT) of the macaque monkey of cquiluminous opponent color stimuli. Exp Brain Res 75:1-14.

Spillmann L, Werner JS, eds (1991) Neurophysiological foundation of visual perception. New York: Academic.

Tanaka K, Saito HA, Fukada Y, Moriya M (1991) Coding visual images of objects in the inferotemporal cortex of the macaque monkey. J Neurophysiol 66:170-189.

Thomas JP (1983) Underlying psychometric functions for detecting gratings and identifying spatial frequency. J Opt Soc Am 73:751-758.

Vaina LM (1989) Selective impairment of visual motion interpretation following lesions of the right occipito-parietal area in humans. Biol Cybern 61:347-359.

Werner JS, Peterzell DH, Scheetz AJ (1990) Light, vision, and aging. Opt Vision Sci 67:214-229.

Zeki S, Watson JDG, Lueck CJ, Friston KJ, Kennard C, Frackowiak RSJ (1991) A direct demonstration of functional specialization in human visual cortex. J Neurosci 11:641-649.

Zihl J, von Cramon D, Mai N (1983) Selective disturbance of movement vision after bilateral brain damage. Brain 106:313-340.

Zihl J, von Cramon D, Mai N, Schmid C (1991) Disturbance of movement vision after bilateral posterior brain damage: further evidence and follow up observations. Brain 114:2235-2252. 